\title{
IMPLANTAÇÃO DE COOPERATIVA MODELO DE CATADORES DE RECICLÁVEIS NO BAIRRO PLANALTO DO PICI, FORTALEZA- CEARÁ-BRASIL
}

Bruna Guilherme do Nascimento - brunaguinas@ hotmail.com Universidade Federal do Ceará

Ronaldo Stefanutti - ronaldostefanutti@ hotmail.com

Universidade Federal do Ceará 


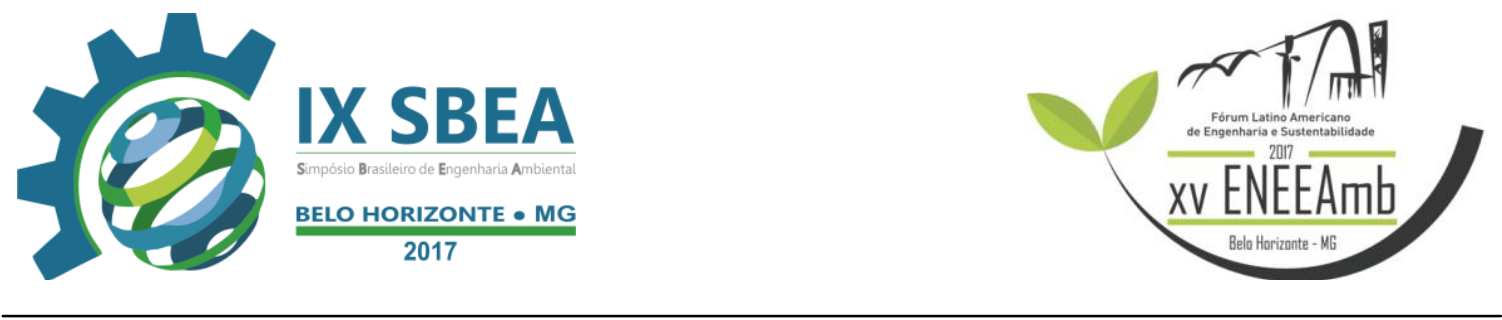

\section{RESUMO}

Muito se discute sobre a importância da reciclagem como contribuição para um desenvolvimento sustentável, assim como sobre a necessidade da propagação da implantação da coleta seletiva nas cidades. Nesse sentido, o presente trabalho se propõe a apresentar, a partir da experiência da implantação de uma cooperativa de trabalho de catadores de materiais recicláveis, desde a análise de viabilidade, à sua formalização e acompanhamento, a possibilidade de concretizar o ideal de desenvolvimento sustentável a partir da coleta seletiva. O projeto tem como base a Lei $\mathrm{n}^{\circ} 12.305$ de 2 de agosto de 2010, a Política Nacional dos Resíduos Sólidos, e busca materializar seus itens aplicáveis no que concerne aos catadores de resíduos, profissionais na área de coleta seletiva, que são geralmente marginalizados e que vivem e trabalham em condições precárias. Além da questão social, há de se perceber o impacto ambiental, à medida que a implantação da coleta seletiva contribuirá para uma maior preservação dos recursos naturais, bem como para uma diminuição nos custos de produção dos produtos que podem utilizar matéria prima reciclada. Haverá ainda uma menor destinação de resíduos aos aterros e uma menor propagação de doenças ligadas ao saneamento básico, que tendem a estar intimamente ligadas aos resíduos depositados incorretamente e aleatoriamente por toda a cidade.

Palavras-chave: Catadores, Cooperativa, Reciclagem.

\section{INTRODUÇÃO/OBJETIVO}

Sustentabilidade e desenvolvimento sustentável são termos que tem sido utilizados de forma recorrente pelas mais diversas áreas de conhecimento e tem, gradativamente, sido integrados ao cotidiano, tanto no ensino como nos ambientes de trabalho.

Conjuntamente, eles pregam, no âmbito ambiental, um consumo consciente, com o mínimo possível de degradação dos recursos naturais que dispõ-se afim de não afetar as necessidades das futuras gerações.

Contudo, tais termos se tornam mais abrangentes à medida que agregam aspectos sociais, econômicos, dentre outros. Para alcançar os objetivos trazidos pelos 
conceitos acima, alguns instrumentos legais, políticos e educacionais são de suma importância.

Dentre os instrumentos da sustentabilidade, pode-se citar a coleta seletiva e a reciclagem, por serem os mais conhecidos pela população e por proporcionarem resultados a curto prazo.

$\mathrm{O}$ ato de reciclar está intimamente ligado à questão da sustentabilidade, uma vez que se propõe a transformar resíduos convertendo-os em matéria prima para processo, trazendo impactos positivos do ponto de vista econômico, social, e ambiental. Ademais, a reciclagem também se mostra importante por trazer benefícios como a diminuição do uso do espaço em aterros sanitários. E a coleta seletiva, além de ter uma associação com a Educação Ambiental, proporciona a execução da reciclagem à medida que os resíduos utilizados na reciclagem devem ser anteriormente separados e tratados de forma adequada.

Segundo o Panorama dos Resíduos Sólidos - estudo feito pela Associação Brasileira de Empresas de Limpeza Pública e Resíduos Especiais (Abrelpe, 2016) -, foi coletado no Brasil 198.750 t/dia em 2015 e a região Nordeste figura como a segunda maior produtora destes resíduos, ficando atrás apenas da região Sudeste, maior polo de concentração econômica e social do país. Entretanto, apesar do enorme volume de resíduos coletados, o estado do Ceará, terceiro estado mais rico da região Nordeste e um dos maiores geradores destes resíduos, destinam apenas $45 \%$ dos resíduos gerados aos aterros sanitários, sendo o restante encaminhado para lixões e aterros controlados.

É válido frisar também que com a reciclagem há uma diminuição da extração de matéria prima e, para alguns materiais, menor gasto energético com a aplicação da mesma. Ademais, os benefícios da reciclagem tem ainda representatividade na área social, por se tornarem uma nova fonte de trabalho, captando uma mão de obra que se não estivesse alocada nesta opção de trabalho, estaria ociosa, devido à falta de capacitação profissional para outras atividades. Com ênfase para a região Nordeste, tem-se que em uma região historicamente conhecida pela vulnerabilidade social, o trabalho com recicláveis independentemente ou por meio de cooperativas, traz oportunidade de geração de renda a quem está fora do mercado de trabalho, e fortalece 
não apenas o indivíduo catador de materiais recicláveis, mas a sociedade e o meio ambiente.

A junção dos termos: sustentabilidade, desenvolvimento sustentável e reciclagem, têm alterado ações e hábitos individuais e coletivos. Seguindo tal tendência, estão as indústrias e empresas que tem se preocupado cada vez mais em promover ações que empreguem tais conceitos. Um exemplo disso é a indústria têxtil, que tem cada vez mais feito o uso de garrafas PET reciclado na produção de tecidos e malhas, cerdas, monofilamentos e cordas. De acordo com Abrelp (2015), dessa forma a indústria que economiza na obtenção de matéria prima, ainda economiza com a reciclagem ao utilizar apenas $0,3 \%$ da energia para a produção da resina virgem e $30 \%$ na produção do poliéster reciclado. Tendo este cenário em vista, é que foi percebida a possibilidade da criação de um elo entre indústria e comunidade, onde haveria uma relação mutualística entre os mesmos.

O presente trabalho é, então, embasado na Lei 12.305 de 2 de Agosto de 2010 na qual é instituída a Política Nacional de Resíduos Sólidos, PNRS -, que estimula a criação deste elo, assim como a inclusão social dos catadores de materiais reutilizáveis e recicláveis e na necessidade de criação de artifícios que executem a coleta seletiva nas cidades brasileiras.

Sendo assim, tal projeto, busca contribuir para a aplicação ampla e efetiva da coleta seletiva na cidade de Fortaleza-CE, a partir do exemplo do bairro modelo Planalto do Pici, bairro este que apresenta uma renda média baixa, produz uma quantidade significativa de resíduos e que se encontra vizinho ao Campus do Pici da Universidade Federal do Ceará, facilitando assim o intercâmbio cultural da Universidade-Comunidade.

Ainda tem-se que, a profissão de catador é reconhecida como categoria profissional oficializada na CBO - Classificação Brasileira de Ocupações- desde 2002, sob registro $\mathrm{n}^{\mathrm{o}}$ 5192-05. E que, passados quinze anos de tal reconhecimento, muitos catadores ainda são marginalizados e buscam, visando uma valorização maior do seu trabalho perante a sociedade e o poder público, se articular coletivamente organizando cooperativas e associações como forma de reconhecimento (IPEA, 2013). 
O trabalho, que foi elaborado e executado pela UFC, surgiu de uma observação da conjuntura geral da cidade de Fortaleza-CE no que concerne à situação dos resíduos sólidos, das políticas voltadas ao meio ambiente e das condições de trabalho e vida dos profissionais que trabalham com coleta seletiva autonomamente.

Com isto, foi percebida a necessidade de uma ação que pudesse vir a demonstrar a aplicabilidade de implantação de uma coleta seletiva, que não fosse excludente com as classes sociais menos favorecidas e que de fato aplicasse a Política Nacional dos Resíduos Sólidos (PNRS).

Deve-se frisar também, que com a implantação de coleta seletiva na cidade, haveria uma diminuição das inundações que costumeiramente assolam a cidade em época de chuvas, deixando áreas intrafegáveis e, por vezes, tirando moradores de suas casas.

Por fim, o presente trabalho tem como objetivos demonstrar a aplicabilidade da coleta seletiva na cidade de Fortaleza- CE, por meio da implantação de um bairro modelo, diminuir a quantidade de resíduos sólidos enviados à aterros, que se encontram em desacordo com a legislação da Política Nacional de Resíduos Sólidos, gerar trabalho e renda à comunidade de baixa renda e promover a aliança entre Comércio-Indústria e Comunidade.

\section{METODOLOGIA}

A fim de se aproximar mais e compreender analiticamente as condições de trabalho e vida dos catadores de resíduos recicláveis, na fase inicial do projeto, foi elaborado um questionário abordando diversos pontos, como: carga horária de trabalho, renda semanal, escolaridade, dentre outros, que foi implantado no bairro Planalto do Pici.

Tal questionário foi aplicado fazendo uso de uma abordagem social, na qual buscava-se conversar com o catador, estabelecer um vínculo de confiança e credibilidade e compreender aspectos mais subjetivos do seu dia a dia, a fim de analisar o modo mais viável de trabalho, tendo em vista que tais profissionais, por serem comumente marginalizados, tendem a não interagirem, especialmente com os de diferentes classes sociais. 


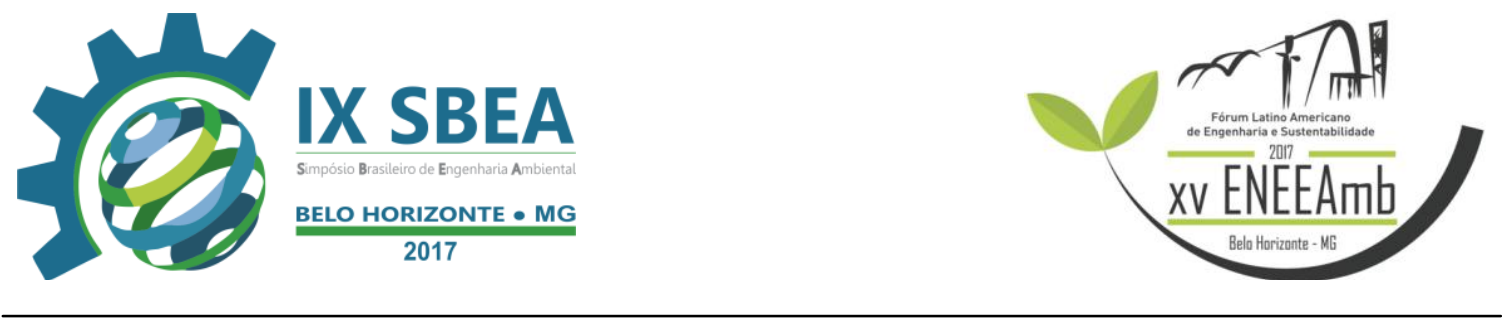

Após a verificação dos dados, chegou-se a conclusão que a implantação de uma cooperativa ou uma associação de catadores em um bairro considerado de baixa renda seria a melhor opção para demonstrar que a coleta seletiva pode ser aplicada na cidade, tendo em vista que o bairro possui 42.494 habitantes (IBGE,2010) e nenhuma cooperativa ou associação nos arredores.

Com isto, foi dado início à organização de encontros de catadores nos quais buscou-se proporcionar uma troca de conhecimentos e opiniões acerca do mercado, das condições de trabalho e das opções que existiam para que a realidade dos mesmos fossem alteradas e o resultado foi a tomada de decisão da implantação de uma cooperativa de trabalho dos catadores de recicláveis no bairro supracitado.

Passou-se então para a fase na qual os catadores, nas reuniões quinzenais, eram capacitados quanto ao cooperativismo, quanto ao gerenciamento de uma cooperativa e quanto às necessidades e métodos de trabalho mais seguros. Concomitantemente, foi dado início a busca por apoio e parcerias que contribuíssem para o fortalecimento da cooperativa.

Com o apoio do Parque de Desenvolvimento Tecnológico da UFC - PADETEC, em 2014, foi oficializada a Cooperativa de Trabalho dos Catadores de Recicláveis do Planalto do Pici e desde então tem sido realizadas reuniões mensais, a fim de acompanhar o desenvolvimento da cooperativa, contribuir em negociações de apoio e cessão de bens, bem como auxiliar nas dificuldades encontradas pela mesma, como para a negociação de um terreno adequado às instalações dos equipamentos.

\section{RESULTADOS E DISCUSSÃO}

Apresentar os dados obtidos, análise e discussão dos resultados. Caso haja necessidade de alguma citação, as equações devem estar centralizadas. Numere as equações em sequência com algarismos arábicos entre parênteses e alinhados à direita, conforme modelo abaixo. Deixe uma linha de espaço antes e depois de cada equação incluída.

A partir da elaboração do Questionário de Perfil Socioeconômico dos Catadores do Planalto do Pici, na fase inicial do projeto, foram obtidas informações pessoais, sociais e econômicas dos entrevistados, dentre as de valor significativo temos as 
seguintes informações na Tabela1. Compilação de dados obtidos do Questionário de Perfil Socioeconômico dos Catadores do Planalto do Pici.

Tabela 1. Compilação de dados obtidos do Questionário de Perfil Socioeconômico dos Catadores do Planalto do Pici.

\begin{tabular}{cccccc}
\hline $\begin{array}{c}\text { No de } \\
\text { Catadores }\end{array}$ & $\begin{array}{c}\text { Idade média } \\
\text { dos } \\
\text { Catadores } \\
\text { (anos) }\end{array}$ & $\begin{array}{c}\text { Tempo médio } \\
\text { de serviço na } \\
\text { Profissão } \\
\text { (anos) }\end{array}$ & $\begin{array}{c}\text { Renda } \\
\text { mensal } \\
\text { média } \\
\text { (R\$) }\end{array}$ & $\begin{array}{c}\text { Média de horas } \\
\text { trabalhadas por } \\
\text { semana }\end{array}$ & $\begin{array}{c}\text { Resíduos } \\
\text { diários } \\
\text { ( Kg por } \\
\text { catador) }\end{array}$ \\
\hline 61 & 58,6 & 9,4 & 545 & 10,7 & 200 \\
\hline
\end{tabular}

É valido frisar, que a partir deste questionário obtivemos que apenas $26 \%$ estudaram até o Ensino Médio, entretanto, sem concluí-lo, tendo o restante estudado apenas até o Ensino fundamental.

Diante de tais dados, é possível perceber as condições adversas de vida e trabalho dos profissionais da coleta seletiva e que seu trabalho é de importância significativa, tendo em vista a quantidade de resíduos que os mesmos coletam.

Na segunda fase, porém, como resultado das reuniões e capacitações realizadas, obtivemos a aceitabilidade de $70 \%$ do grupo de catadores para a formação de uma cooperativa de trabalho.

E, em 2015, a cooperativa CATPICI foi fundada, contando com 14 catadores na diretoria, sendo o cargo de presidência ocupado por uma mulher, por meio de votação.

Após sua fundação, a CATPICI passou a contar com o apoio oficial da Universidade Federal do Ceará- UFC-, do Parque de Desenvolvimento Tecnológico da UFC (PADETEC), do Centro de Desenvolvimento Familiar (CEDEFAM), da Secretaria de Desenvolvimento Social e do Trabalho e da Secretaria de Urbanização e Meio Ambiente de Fortaleza e do Ministério Público do Estado do Ceará.

Tendo cada um destes órgãos, contribuído para a formação, com ênfase para o CEDEFAM, que cedeu suas instalações para a realização das reuniões, e para o PADETEC que auxiliou com a parte burocrática ligada à formalização da cooperativa. 


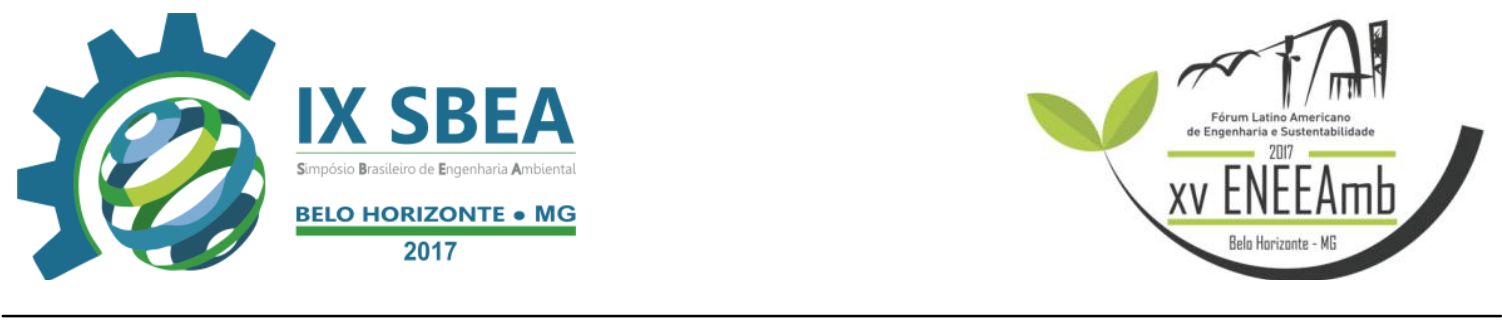

Entretanto, a CATPICI encontra-se hoje sem o seu galpão oficial de triagem de resíduos, sendo a triagem executada em dois núcleos diferentes, e sem contar com os aparelhos necessários que se encontram guardados, esperando um galpão adequado.

Tal empecilho se dá devido a falta de recursos financeiros para o aluguel de um terreno e galpão adequados, embora, de acordo com a PNRS, em seu art. 42, que afirma que o poder público deverá atender prioritariamente, com linhas de financiamento, iniciativas para a implantação de infraestrutura física e aquisição de equipamentos para cooperativas ou outras formas de associação de catadores de materiais reutilizáveis e recicláveis formadas por pessoas físicas de baixa renda, tais recursos deveriam ser advindos de medidas públicas já previstas em lei.

\section{CONCLUSÕES/RECOMENDAÇÕES}

Com o presente trabalho pode-se perceber a dificuldade de implantação de uma cooperativa de catadores, em um contexto que à priori se mostra favorável, mas que, entretanto, se concretiza como árduo. O trabalho que teve seu início em 2014, embora tenha tido empenho e agilidade por parte dos catadores, teve seu sucesso condicionado à ações políticas, que não se mostram sensíveis à causa social e ambiental.

Deve-se salientar, com base neste caso, temos que embora promissora para a resolução do problema ambiental da grande geração de resíduos sólidos, a implantação de cooperativas de catadores de recicláveis para execução de coleta seletiva na cidade de Fortaleza-CE só será viável com a aplicação efetiva da Política Nacional de Resíduos Sólidos, devendo haver assim linhas de crédito para a promoção destas cooperativas e suas expansões, bem como os órgãos ambientais deverão adotar políticas de apoio e treinamentos para os interessados, a fim de capacitá-los para a formação de cooperativas e conscientizá-los da importância da execução dos seus trabalhos.

\section{REFERÊNCIAS BIBLIOGRÁFICAS}

ABRELP, Panorama dos Resíduos Sólidos no Brasil 2015. Disponível em: www.abrelpe.org.br/Panorama/panorama2015.pdf. Acesso em: 9 mar. 2017.

CBO, Listagem das Profissões Regulamentadas. Disponível em: www.mtecbo.gov.br/cbosite/pages/regulamentacao.jsf. Acesso em: 7 mar. 2017. 


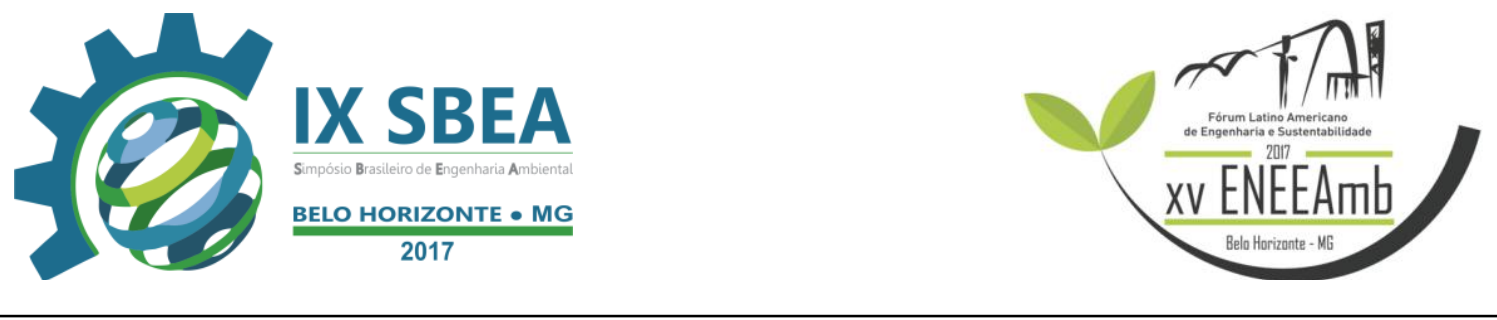

IBGE: Instituto Brasileiro de Geografia e Estatística. Disponível em: www.ibge.gov.br. Acesso em 29 mar. 2017.

IPEA, Brasil Situação Social das Catadoras e dos Catadores de Material Reciclável e Reutilizável. http://www.ipea.gov.br/agencia/images/stories/PDFs/situacao_social/131219_relatorio_ situacaosocial_mat_reciclavel_brasil.pdf. Acesso em: 30 mar. 2017.

Lei $N^{o} 12305 / 2010$, Institui a Política nacional de resíduos sólidos. Disponível em: www.mma.gov.br/port/conama/legiabre.cfm?codlegi=636. Acesso em: 4 mar. 2017.

Lei $\mathrm{N}^{\mathrm{o}}$ 12690/2012, Das Cooperativas de Trabalho. Disponível em: www.planalto.gov.br/ccivil_03/_Ato2011-2014/2012/Lei/L12690.htm. Acesso em 5 mar. 2017. 